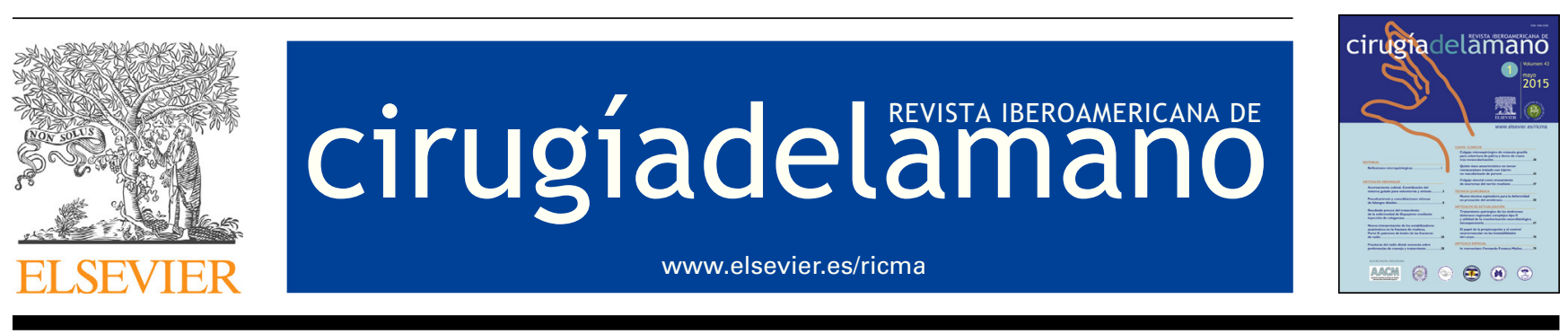

\title{
Cirugía de la Mano: dos aspectos
}

\author{
Hand Surgery: two aspects
}

Quiero agradecer la oportunidad de escribir un editorial al Director y Redactor de la Revista y aprovecharla para tratar dos temas que me parecen fundamentales para el desarrollo y sostenibilidad de la Cirugía de la Mano, no solo en España sino también en el resto del mundo donde esta subespecialidad o especialidad es considerada, como son la formación y los honorarios médicos en la práctica privada. Todo ello corriendo el riesgo de ser malinterpretado en ese último aspecto.

Respecto de la formación en Cirugía de la Mano, resaltar la falta de interés en estamentos oficiales, tanto de sanidad como de educación, en realizar un plan de formación. En la formación de grado, frecuentemente no son los profesionales dedicados a esa parcela los que imparten la enseñanza de la patología de la mano, tanto en lo relativo a la asignatura de Cirugía Ortopédica y Traumatología (COT) como de Cirugía Plástica Reparadora y Estética (CPRE). En lo relativo a postgrado o subespecialización, está pendiente de desarrollarse, tras la promulgación de la ley de troncalidad, otras Áreas de Capacitación Específica (ACE), pero no se ha observado ninguna acción oficial para considerar a la Cirugía de la Mano como tal (ACE). Solamente la SECMA, en dos ocasiones, ha presentado una memoria ante el Ministerio de Sanidad (Dirección General de Ordenación Profesional) sobre la necesidad de la creación de una ACE, con el apoyo de las sociedades científicas de las dos especialidades implicadas. Según la ley de Troncalidad antes mencionada, deben de ser las Comisiones Nacionales de esas Especialidades implicadas en la creación de la ACE, las que deben elevar la solicitud de su creación. En este caso COT y CPRE. La SECMA tratará de influir en esas comisiones para que puedan elevar la petición ante el Ministerio.

En lo relativo al tema de honorarios médicos de la medicina privada, se entiende el de las compañías de seguros, aclarar en primer lugar la necesidad de su existencia en el momento actual en que la medicina pública, que si bien ofrece una cobertura global en todos los aspectos, no puede realizarla en el tiempo necesario. Es por ese motivo que una parte importante de la población tiene suscritas pólizas sanitarias con las que intenta paliar las carencias del sistema público. Aclarado este punto para evitar una mala interpretación de la preocupación por la sanidad privada, paso a concretar los motivos de la misma. Por un lado y habida cuenta de todo lo necesario para llevar a cabo la actividad privada, los honorarios médicos percibidos por nuestra actividad concreta, en muchos casos no cubren los gastos ocasionados para desarrollarla con todas las garantías legales y necesarias. Esto solo, ya pone en peligro la sostenibilidad del sistema. Por otro lado, las compañías de seguros, muchas de ellas, han creado sus propios centros de prestación de servicios, y la mayoría de los profesionales que prestan sus servicios en ellos lo hacen con contrato laboral. Con ello se abole el pago por acto médico y esta parte de la medicina privada pierde su carácter original. Otro aspecto que incide en esa "desnaturalización" es el desarrollo de empresas de hospitales que, en su crecimiento empresarial para mejorar su posición de cara a poder negociar precios con las compañías de seguros por la prestación de sus servicios, negocian de forma global esta prestación incluyendo los honorarios médicos, convirtiéndose, así, en intermediarios entre las compañías de seguros y los profesionales, excluyendo a éstos de cualquier participación. En este sentido la profesión ha perdido poder debido a la desunión de los médicos y a la pasividad de las organizaciones colegiales.

La respuesta de la SECMA ante el aspecto de la formación debería ser elaborar un plan para poder ofrecer su colaboración al Ministerio y en cuanto al segundo tema, creo que toda acción que pueda encaminarse a mejorar esta situación debería estar apoyada por las organizaciones colegiales, a las que deberíamos de influir, porque son las que deberían aglutinar los esfuerzos de sus colegiados en defensa de sus intereses.

Ángel Ferreres Institut Kaplan

Correo electrónico: angelferreres@institut-kaplan.com 